\title{
Sixteen Fractures in a Seven-Month- Old Child Caused by Nonaccidental Trauma
}

\author{
Mehmet Burtaç Eren ${ }^{a} \quad$ Erkal Bilgiça Selçuk Çetin ${ }^{b}$ Faik Alev Deresoy ${ }^{c}$ \\ Tahir Öztürk ${ }^{a}$ Orhan Balta ${ }^{a}$ \\ aDepartment of Orthopaedics and Traumatology, Gaziosmanpasa University School of \\ Medicine, Tokat, Turkey; ${ }^{b}$ Department of Forensic Medicine, Gaziosmanpasa University \\ School of Medicine, Tokat, Turkey; 'Department of Pathology Tokat, Gaziosmanpasa \\ University School of Medicine, Tokat, Turkey
}

\section{Keywords}

Nonaccidental trauma - Physical child abuse · Pediatric trauma - Pediatric multifracture

\begin{abstract}
Definition of physical child abuse is used to refer to a casualty injured by the caregiver. Healthcare professionals providing medical care are responsible for detecting and reporting child abuse. A 7-month-old pediatric patient was referred to us from an outer center with the diagnosis of multiple fractures (14 different bones in 16 different anatomical regions). Skeletal pathologies were evaluated after exclusion of head and abdomen injuries in the emergency department. This child with fractures in 16 different anatomical regions of 14 different bones in her body is alive and does not have an intracranial injury. The number of fractures was too high to be explained even by major trauma. If child abuse is suspected, relevant authorities should be notified immediately. Medical records must be meticulously done as they can contribute to the possible court process. Our case, which contains almost all of the history and physical examination and risk factors of typical child abuse, is instructive enough to guide any health-care professional who may encounter this issue. The threshold in deciding on reporting of child abuse should be low. Every suspicious case should be reported in order to prevent repetitive abuse.
\end{abstract}

(C) 2021 The Author(s).

Published by S. Karger AG, Basel

\section{Introduction}

The definition of nonaccidental trauma (NAT) refers to an injury through assault [1]. In many countries, the obligation to notify health-care professionals who provide medical care for suspected NAT is regulated by law. It is recommended that notification is made under the

\section{Karger $\stackrel{\text { ! }}{=}$}


supervision of law enforcement or security officers to prevent recurring violence. NAT is one of the most important causes of mortality in childhood [2]. Mortality due to NAT is often associated with head trauma. Suspected cases should be assessed for head trauma.

The history of the patient is very important for evaluation of NAT. The patient's history often has basic characteristics. No history of trauma or rejection of trauma [1]; unreasonable explanations of the type and severity of the injury, incompatible with the child's level of development; excessive unexplained delay for medical admission; additional injury due to resuscitation at home [3]; remarks changed during re-interrogation or contradicting other observers; and attempts to assign blame to pets or siblings constitute the distinctive content of patient history.

In cases where abuse is considered, the evaluator should examine intraoral, auricle, scalp, hip circumference, anogenital region, and neck folds. Injury pattern or shape should match the given story and the injury (cable loop marks, slap marks, belt buckle marks, bites, and immersion burns).

Bruises and swelling in the scalp and fontanels, tears in the tragus, oral cavity, buccal mucosa, signs of labia - labial frenula, bruises and abrasions in the neck and folds, bruises and redness due to trauma in the hips, genital area injuries, and palmar injuries are highly associated with NAT. Fractures are a common finding of physical child abuse. Therefore, the skeletal survey is important in cases that are considered suspicious. All children younger than 24 months, who may have been subjected to physical abuse, should be evaluated with a skeletal survey [4]. Even one fracture is enough for suspecting NAT for nonambulatory children. Multiple fractures and improvement in different stages in children without metabolic disease are typical for child abuse. Multiple fractures have been reported in $80 \%$ of cases younger than 1 year [5].

The illogicality of the injury mechanism in metabolic bone diseases is similar to the cases of physical abuse. Therefore, metabolic bone diseases should be kept in mind in differential diagnosis. However, the fact that children with chronic diseases are abused at a higher rate should be considered, and the possibility of physical abuse should not be overlooked in cases with known metabolic bone disease [6]. The current study aimed to present a NAT case hospitalized for multiple fractures.

\section{Case Report/Case Presentation}

A 7-month-old girl was directed to us from the first application center. The mother stated that while they were visiting relatives in a foreign city, they applied to the emergency room recommended by their relatives. The baby was with her mother only, and her father was on his way to come from outside the city. The patient's history was first obtained from her mother; she stated that the girl fell 15 days ago while being placed in her cradle by her father. She therefore had a plaster-splint (right long leg splint and left long leg circular plaster) applied in the hospital they visited.

Physical examination revealed general irritability, pain with slight palpation in each extremity, swelling in both knees and ankles, and swelling and pain in both elbows and forearms. The vascular examination was normal. Light reflex in both eyes was natural, and the patient had high irritability during the examination and could not cooperate for abdominal examination. A significant deformity was observed in the sagittal plane of both knees, and almost total edema was seen in both arms. Genitourinary system examination was normal.

Skeletal survey, brain computerized tomography, and abdominal ultrasonography examination were performed. After skeletal survey, all fractures has detected and recorded. In

\section{Karger'}




\section{Case Reports in Orthopedic Research}

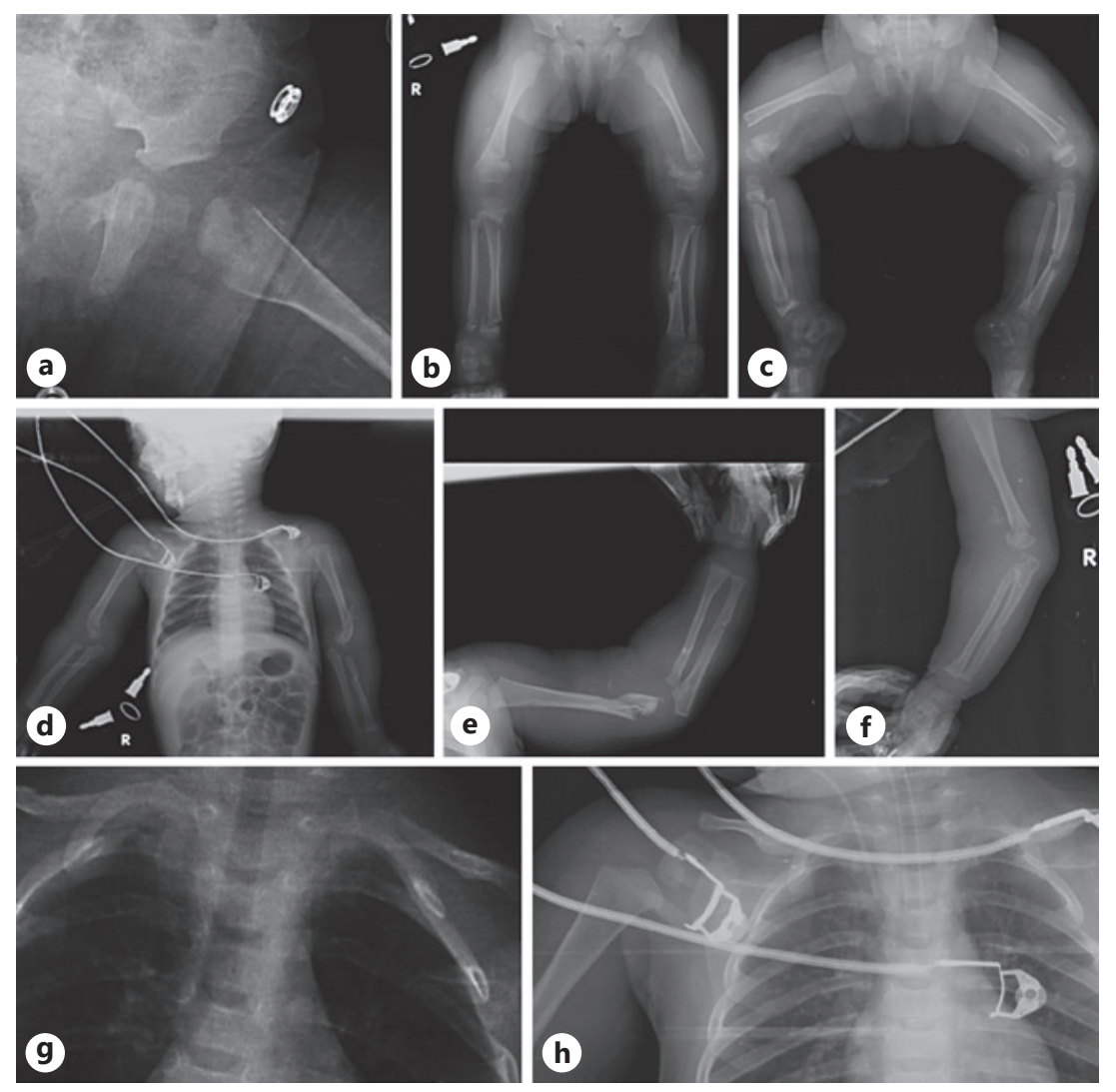

Fig. 1. Fracture sites detected in the skeletal survey, $R$ supracondylar humerus fracture (d, f), $R$ distal tibia fracture $(\mathbf{b}, \mathbf{c}), \mathrm{R}$ distal fibula fracture $(\mathbf{b}, \mathbf{c})$, R proximal tibia fracture $(\mathbf{b}, \mathbf{c})$, L supracondylar humerus fracture ( $\mathbf{d}, \mathbf{e})$, R distal radius fracture (d, f), R ulna segmental shaft fracture (d, f), L radius shaft fracture (d, e), L ulna shaft fracture (d, e), L supracondylar femur fracture (b, c), R supracondylar femur fracture (b, c), L tibia shaft fracture (b, c), L medial clavicle fracture (g), L femur subtrochanteric fissure (a), L acetabulum fracture (a), and R 1st rib fracture (h) were detected. In addition to these findings, common periosteal reactions were observed in the anterior and posterior femur in both thighs (b, c). R, right; L, left.

addition to detection fractures, common periosteal reactions were observed in the femur anterior and posterior in both thighs (shown in Fig. 1).

The patient, whose brain computerized tomography and all abdominal ultrasonography results were reported as normal, was referred for ophthalmic examination at the ophthalmology clinic. After fundus examination, they have stated that there were no signs of retinal hemorrhage. After initial assessment was completed, the patient was hospitalized in orthopedics and traumatology service.

It was decided to report the case to the official authorities with the suspicion of physical child abuse, taking into account the clinical features of the case (after the event, the time has passed until the admission, multiple fractures in the immobile infant). Detailed history and examination assessment was performed in the forensic medicine unit. When the anamnesis was taken under the supervision of different forensic medicine physicians separately from the parents, the mother made statements that contradicted her first anamnesis. The father stated that it might have happened when the mother was out of town for treatment and the grandmother was looking after the child. Statements, incompatible with the severity of the injury, such as pulling and dragging by the 8-year-old brother, were added to the story. 


\section{Case Reports in Orthopedic Research}
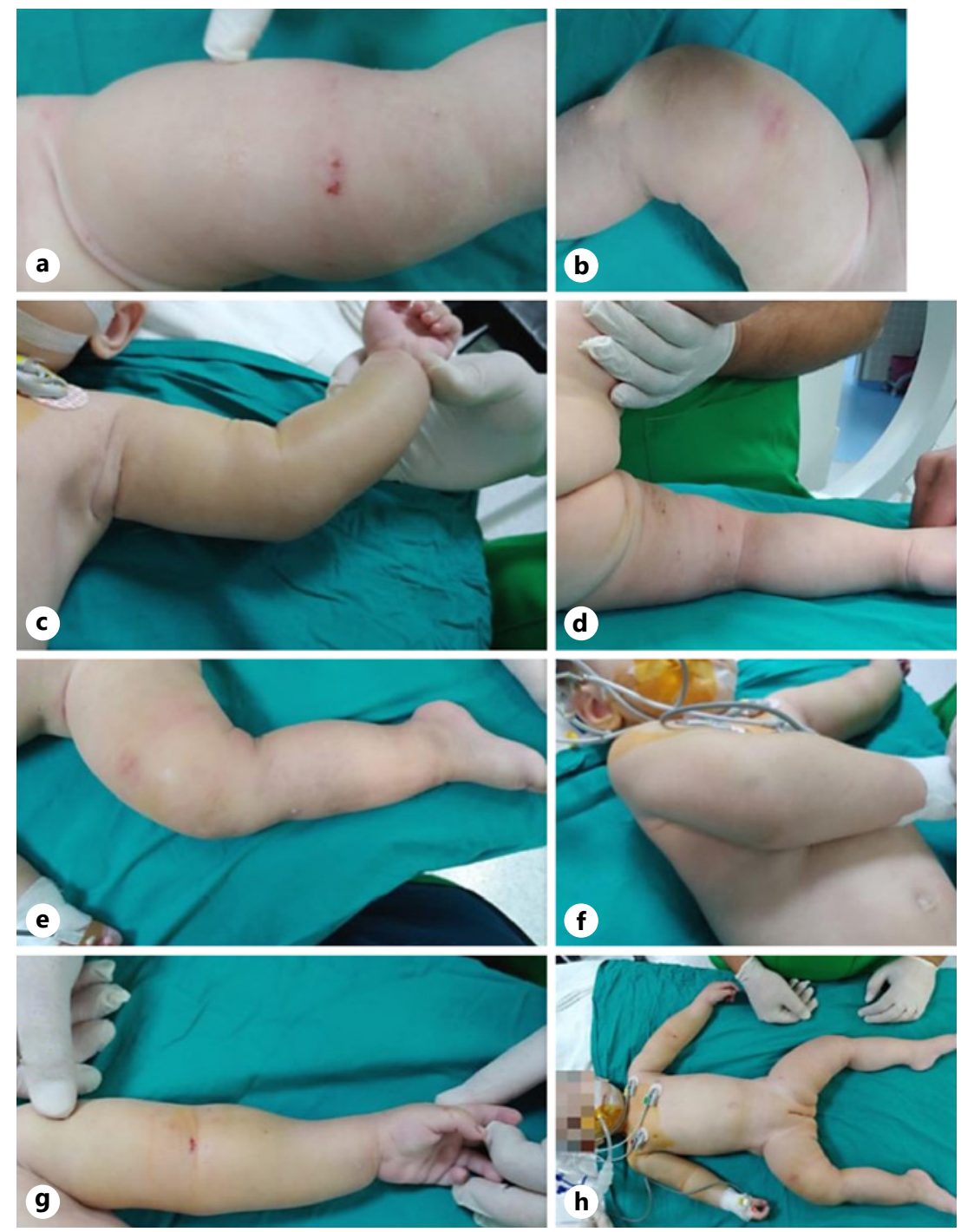

Fig. 2. Detailed clinical photographing under general anesthesia; ecchymosis on the L thigh distal $1 / 3$ anterior and $2 \times 5$-mm-wide deep dermabrasion (a), $1 \times 1-\mathrm{cm}$ circular ecchymosis on the $\mathrm{R}$ thigh anterior (b), extensive edema and ecchymosis on the L upper extremity (c), 5-mm-wide dermabrasion on the $\mathrm{L}$ thigh posterior (d), $5 \times 100$-mm circular ecchymosis starting from the $\mathrm{R}$ thigh anterior to the posterior $(\mathbf{e}), 1 \times$ 1-cm ecchymosis in the R arm posterior (f), 5-mm-wide dermabrasion in the L elbow anterior (g), and general view were recorded by photography (h). L, left; R, right.

The patient was taken to the 3rd level pediatric intensive care unit where she could be monitored continuously and followed up without an attendant. Anesthesia consultation was requested. Although there is a low probability of possible metabolic diseases, alkaline phosphatase, calcium, and serum vitamin D3 $(25-\mathrm{OH})$ levels were studied. It was observed that alkaline phosphatase was $325 \mathrm{U} / \mathrm{L}$, calcium $12.6 \mathrm{mg} / \mathrm{dL}$, phosphorus $4.34 \mathrm{mg} / \mathrm{dL}$, and vitamin D3 (25-OH) $42.42 \mathrm{ng} / \mathrm{dL}$ were within normal limits. Preoperative hemoglobin was $7.4 \mathrm{~g} / \mathrm{dL}$, and $50 \mathrm{cc}$ erythrocyte suspension replacement was performed to prepare for surgery.

General anesthesia was administered with endotracheal intubation. Detailed examination was performed under anesthesia (shown in Fig. 2). 

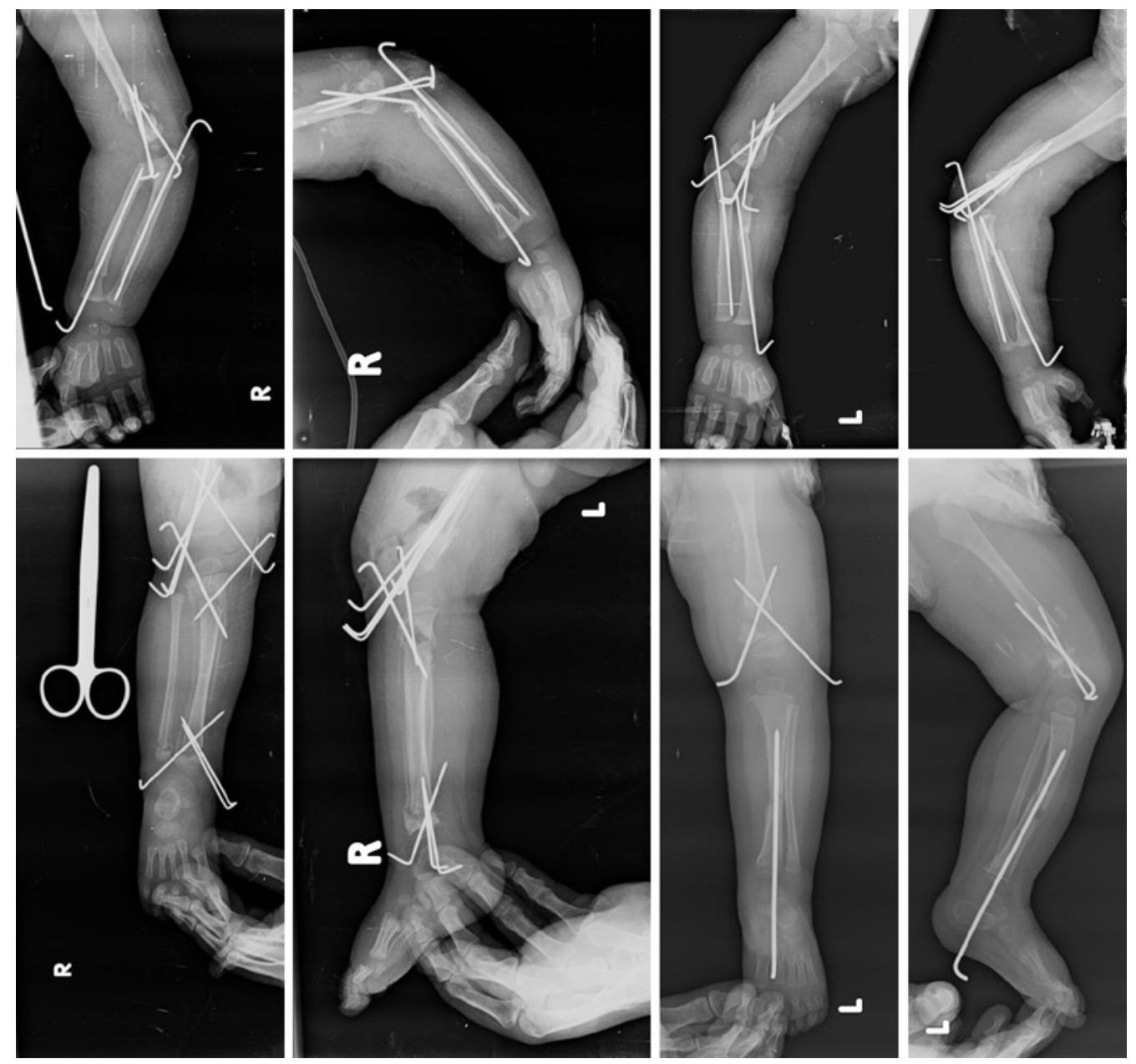

Fig. 3. Postoperative radiographs of the patient.

Osteosynthesis was done using closed reduction and cross K-wire for both supracondylar humerus fractures, right distal tibia fracture, right proximal tibia fracture, and left supracondylar femur fracture. Subsequently, closed reduction and intramedullary K-wire fixation were performed for the both radius, both ulna, and left tibia fractures. Osteosynthesis of the right distal femur was performed using open reduction and fixation with K-wires. A biopsy was taken from the callus tissue from this area and sent to pathology (shown in Fig. 3).

After the operation, pelvipedal plaster and long arm splint on both upper extremities were applied. During the follow-up of the patient, the pathology result was recorded. In the Tru-Cut biopsy findings were interpreted as a normal bone healing and did not support metabolic bone disease.

The patient was hospitalized for 48 days, during which the social service and legal process continued. At the end of 48 days, according to the preliminary decision, the splints and pelvipedal plaster were removed, and the patient was discharged by the social services department. $\mathrm{K}$-wires were removed after 2 weeks after the completion of the union in all fractures at the 2nd month control.

Last control of the patient was performed at the 6th month. The range of motions was recorded; the elbow range of motion is $0-140^{\circ}$, the left knee range of motion is $0-120^{\circ}$, and the right knee range of motion is $0-100^{\circ}$ was observed. 
Case Reports

in Orthopedic

Research

\begin{tabular}{l|l}
\hline Case Rep Orthop Res 2021:4:185-191 \\
\hline DOI: 10.1159/000517768 & $\begin{array}{l}\text { @ 2021 The Author(s). Published by S. Karger AG, Basel } \\
\text { www.karger.com/cio }\end{array}$ \\
\hline
\end{tabular}

Eren et al.: Sixteen Fractures in a Seven-Month-Old Child

\section{Discussion/Conclusion}

King et al. [7] reported that the average age of abuse was 7 months in their study of 429 fractures in 189 injured children with $69 \%$ of the physical abuse fractures detected in children younger than 1 year.

In our case, multiple fractures in a nonambulatory child are highly suspicious. The metabolic bone disease was excluded on the basis of laboratory and tissue tests. In a 7-month-old child without metabolic disease, a total of 16 different bones is an obvious finding of recurrent, severe trauma.

The inability to explain the findings of significant trauma is a reliable marker for abuse. Another common situation in the physical abuse story is the crime attribution on the siblings. Clark et al. [8] revealed that the rate of attribution to sibling was 38\% in the stories of patients who were diagnosed with burns in the pediatric emergency department and that there was a significantly more frequent findings in cases of abuse.

The inconsistencies in the history of the case and the inability to explain the existing injury seem remarkable. Almost all of the content of the story was seen together in physical abuse. Shifting the blame to the younger brother, late admission to the hospital, contradictory statements, and accusations of other family members are frequent signs of abuse.

A late application is known to be common in cases of abuse compared to accident injuries $[9,10]$. Farrell et al. [9] retrospectively evaluated 206 children $<6$ years admitted with fractures. They reported $21 \%$ of physical abuse if the admission was delayed for $>8 \mathrm{~h}$ after the fracture [9]. Although our patient was admitted to our hospital 15 days before we saw her, the widespread periosteal reactions suggested that there were woven bone areas in the diagnosis of pathology at least 1 week between being admitted to the hospital after being subjected to violence.

Even if surgical treatment is not indicated in fractures, hospitalization until the completion of the examination of suspected abuse is indicated [11]. The social services department should be notified during the stay.

If misdiagnosed, child abuse leaves the victim at risk of repetitive abuse. When notifying social services and judicial authorities, even the slightest doubt should not be ignored.

\section{Statement of Ethics}

This study was conducted ethically in accordance with the World Medical Association Declaration of Helsinki. The authors have no ethical conflicts to disclose. Informed written consent was obtained from the patient's parent for publication of this case report and the involved images. No information identifying the patient was included. The report is exempt from ethical committee approval because it does not involve intervention other than standard medical care.

\section{Conflict of Interest Statement}

The authors have no conflicts of interest to disclose.

\section{Funding Sources}

No funding was received.

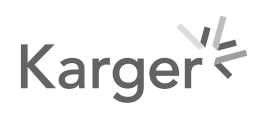


Case Reports

in Orthopedic

Research

\begin{tabular}{l|l}
\hline Case Rep Orthop Res 2021:4:185-191 \\
\hline DOI: 10.1159/000517768 & $\begin{array}{l}\text { @ 2021 The Author(s). Published by S. Karger AG, Basel } \\
\text { www.karger.com/cio }\end{array}$ \\
\hline
\end{tabular}

Eren et al.: Sixteen Fractures in a Seven-Month-Old Child

\title{
Author Contributions
}

\author{
A. Mehmet Burtaç Eren. \\ B. Erkal Bilgiç. \\ C. Selçuk Çetin. \\ D. Faik Alev Deresoy. \\ E. Tahir Öztürk. \\ F. Orhan Balta.
}

A.B. and B.C. conceived of the presented idea. A. developed the theory and performed the computations, collected data, and wrote the manuscript with support from B.C.D.E.E.F. C.D.E. and $\mathrm{F}$. verified the analytical methods.

\section{Data Availability Statement}

The datasets used and/or analyzed during the current study are available from the corresponding author on reasonable request.

\section{References}

1 Christian CW, Committee on Child Abuse and Neglect. The evaluation of suspected child physical abuse. Pediatrics. 2015;135(5):e1337-54.

2 Roaten JB, Partrick DA, Nydam TL, Bensard DD, Hendrickson RJ, Sirotnak AP, et al. Nonaccidental trauma is a major cause of morbidity and mortality among patients at a regional level 1 pediatric trauma center. J Pediatr Surg. 2006;41(12):2013-5.

3 Hettler J, Greenes DS. Can the initial history predict whether a child with a head injury has been abused? Pediatrics. 2003;111(3):602-7.

4 Belfer RA, Klein BL, Orr L. Use of the skeletal survey in the evaluation of child maltreatment. Am J Emerg Med. 2001;19(2):122-4.

5 Leventhal JM, Gaither JR. Incidence of serious injuries due to physical abuse in the United States: 1997 to 2009. Pediatrics. 2012;130(5):e847-52.

6 Jaudes PK, Diamond LJ. The handicapped child and child abuse. Child Abuse Negl. 1985;9(3):341-7.

7 King J, Diefendorf D, Apthorp J, Negrete V, Carlson M. Analysis of 429 fractures in 189 battered children. J Pediatr Orthop. 1988;8(5):585-9.

8 Clark KD, Tepper D, Jenny C. Effect of a screening profile on the diagnosis of nonaccidental burns in children. Pediatr Emerg Care. 1997;13(4):259-61.

9 Farrell C, Rubin DM, Downes K, Dormans J, Christian CW. Symptoms and time to medical care in children with accidental extremity fractures. Pediatrics. 2012;129(1):e128-33.

10 Wood J, Rubin DM, Nance ML, Christian CW. Distinguishing inflicted versus accidental abdominal injuries in young children. J Trauma Acute Care Surg. 2005;59(5):1203-8.

11 Wood J, Callahan J, Christian C. Child abuse/assault. Textbook of pediatric emergency medicine. Philadelphia, PA: Wolters Kluwer; 2016. p. 663.

\section{Karger'}

